\title{
The Impact of Wellness Programs on Employee Job Satisfaction in Colleges and Universities
}

\author{
Donel J. Richemond ${ }^{1}$, Charles Needham ${ }^{2}$ \\ ${ }^{1}$ University of Central Florida, Orlando, Florida, USA \\ ${ }^{2}$ Jarvis Christian College, Hawkins, Texas, USA \\ Email: donelrichemond@gmail.com,charlesneedham@yahoo.com
}

How to cite this paper: Richemond, D.J. and Needham, C. (2020) The Impact of Wellness Programs on Employee Job Satisfaction in Colleges and Universities. Open Journal of Business and Management, 8 , 569-599.

https://doi.org/10.4236/ojbm.2020.82035

Received: January 20, 2020

Accepted: February 28, 2020

Published: March 2, 2020

Copyright $\odot 2020$ by author(s) and Scientific Research Publishing Inc. This work is licensed under the Creative Commons Attribution International License (CC BY 4.0).

http://creativecommons.org/licenses/by/4.0/

\begin{abstract}
This study examines the impact of wellness programs on employee job satisfaction in Colleges and Universities. Utilizing a sample of full time or part time college and university faculty members of for-profit and brick and mortar universities in the United States, the results of this correlational study did not predict job satisfaction among employees who participated in wellness programs. In addition, it was found that interaction analyses indicated a relationship between gender and job satisfaction. Females were more likely than males to have higher levels of job satisfaction, as well as years of experience and job satisfaction. Faculty who had employed between 11 and 15 years were more likely to have higher levels of job satisfaction.
\end{abstract}

\section{Keywords}

Healthcare System, Job Satisfaction, Motivation, Profitability, Relationship, Wellness Programs

\section{Introduction}

Employees are important organizational assets [1]. Organizational leaders rely on employees to assist in achieving their objectives by performing effectively and efficiently and helping to implement strategies for outperforming their competition. Employee satisfaction can predict their degree of work performance.

Employee or job satisfaction relates to employees' feelings and perceptions about different aspects of their jobs, for example, satisfaction with supervisors [2]. Employee dissatisfaction with work has associations with psychological and physical well-being [1]. Dissatisfied employees will often seek ways to avoid work and evade their responsibilities [2].

Organizations that create efficacious wellness programs anticipate that for 
example, a wellness program can increase employee satisfaction and performance [3]. Employers' goals are to design a work environment that cultivates a psychosocial climate in the organization characterized by the opportunity for career growth [4]. Considering that employers adopt wellness programs in order to improve work relationships and to encourage employees to live a healthy lifestyle, more research on the topic of employee wellness is necessary [5].

\section{Background of This Study}

Job satisfaction is becoming a key factor in improving employees' working environments [1] [2] stated that researchers have demonstrated that job satisfaction improves absenteeism and organizational productivity. Ascertaining employee satisfaction is important for the performance of the employees of the organization [2]. Employee Satisfaction creates a more productive workforce in the organization that can reduce absenteeism [1].

Wellness programs could improve employees' degree of satisfaction and affect productivity and other behaviors. The nature of the relationship between the effectiveness of wellness programs and employee satisfaction is unknown. Limited research exist between Wellness program organizations and the relationship between wellness programs and employee satisfaction [6].

Sponsoring a comprehensive wellness program can prove costly [six]. Many employees do not participate in wellness programs. Wellness programs can increase operational costs for management and lessen the chances for effectiveness within the organization [2]. Wellness programs are gaining popularity among organizations' leaders [2].

\subsection{Healthy Work and Organizational Review}

The concept of healthy work organization drew the attention of researchers who defined it as an organization with accessible and equitable opportunities for career growth and improvement of work-life [4]. Healthy work organizations can include a supportive social-organizational environment and offer meaningful and well-designed jobs [4]. Organizational arrangements include health-related programs that constitute part of well-designed jobs.

The healthy work organization became a theoretical model synthesizing core elements that researchers viewed as essential [4]. The model contained diverse elements. Organizational climate, emphasizing the social and interpersonal facets of the work environment, encompasses organizational support, co-worker support, involvement and participation, communication, and health and safety climate. Job design captures employees' subjective perceptions of their work activities. The design includes workload, autonomy, control, job content, role clarity, environmental conditions, and work schedule. Job future needs to emphasize job security, equity, career development, encompasses job security, pay and promotion equity, learning opportunities, and flexible work arrangements. A 
healthy work organization includes core organizational attributes, psychological work adjustment, and employee health and well-being [4].

The study includes a sample of 1130 employees recruited from nine stores of a large retailer [4]. A questionnaire consisting of 194 items and reflecting 29 first-order constructs underwent an initial content validation by a panel of three experts from the National Institute of Occupational Safety and Health. Exploratory factor analyses and confirmatory factor analyses followed. The major dimensions of the questionnaire were organizational attributes, organizational climate, job design, job future, psychological work adjustment, and employee health and well-being [7].

The analysis includes compelling evidence that works attributes influenced employees' psychological work adjustment, which in turn affected their health and well-being [4]. Numerous studies report a link between specific work characteristics and various aspects of health and well-being [4]. No prior study includes a comprehensive model with the capacity to explain the complex interrelationships among the various factors [7].

The results of the model revealed a good fit, with significant links among the array of variables examined. Through the findings, Spreitzer and Porath (2012) highlighted the pivotal role of organizational climate in organizational effective. The organizational climate factors relate to providing employees with social support. Participation and interaction with colleagues and supervisors or others in the work environment constitute direct support [7] [8]. Indirect support occurs by creating a supportive atmosphere.

Dejoy et al. (2010) indicated that some researchers' social dimension of work is probably the least understood and the most intriguing. The perspective has a significant influence on the effectiveness and efficiency of the organization. The relationship between employees and managers is an important but often overlooked aspect of employee empowerment strategies [4]. Both formal and informal types of social support are important to employee health. Human resource management practices often emphasize the creation of a supportive work environment. Strategies include promoting a culture of teamwork, encouraging collaboration, and entrenching cooperation. Techniques would include creating a buddy system, employee support groups, matching mentors, protégés, training managers, and employees in social support. The idea of cultivating a supportive workplace arose from the perspective that a substantial body of evidence existed, demonstrating a link between social support and health [4].

Dejoy et al. (2010) examined the impact of a healthy work organization intervention involving 21 stores from a national retail chain. The study design arose from four major goals. The goal of the study consists of assessing the effects of the intervention over time through a follow-up period of at least one year. The next goal is comparing intervention and control stores in the same retail chain in terms of employee health and well-being. The next goal is using the work site as a unit of analysis and making use of an intervention drawn from relevant orga- 
nizational and behavioral theory. The participating stores represented four districts; two districts served as the intervention group (10 stores), and two districts served as the control group (11 stores). Longitudinal studies typically have some attrition; the sample consisted of 2207 employees at the pretest assessment, 1723 at the posttest, and 1510 employees at the follow-up survey [4].

The overall goal of the intervention was to create a healthy work organization, and the intervention includes employee involvement and problem-solving [4]. An Action Team, an employee problem-solving team (8 - 10 members), at each site featured members from all departments and levels. The teams had the responsibility of developing, implementing, and evaluating targeted action plans related to issues within the store as identified by the team members. A trained facilitator worked with the teams on their action plans, utilizing a five-stage problem-solving process, familiarization, skill building, prioritization, action, and reaction. Teams use a manual to guide the work. External facilitation gradually decreased so the teams became independent and self-sustaining. Each team worked on problems unique to that store and devised their activities, strategies, and goals [4].

The intervention of the study took place at three levels [4]. Except for business performance, all the measures they examined came from employee surveys based on the theoretical model of a healthy work organization tested by DeJoy et al. (2010). The study period was a turbulent time for the retail chain [4]. The team problem-solving intervention seemed to mitigate some of the detrimental effects of the external conditions. Both the intervention and control stores suffered declines in business performance, but the decline was much sharper for the control stores [4].

Similarly, job satisfaction and commitment declined during this period, but to a greater degree in the control group stores. A notable finding was that stress stayed low for the employees in the action team stores, which is striking because of the stress associated with organizational change and upheaval [9]. In contrast, stress levels rose among the employees in the control group stores [4].

Success for the intervention was less than the team expected from the two factors they designed for capturing empowerment, work self-efficacy, and impact [4]. The near-failure might have resulted from problems some of the teams experienced in carrying out their action plans to make changes in the store. To some extent, the near-failure was attributable to the upheaval in the organization, although that would reveal speculative [8]. The impact of the intervention on employee health and business performance was not as strong as the researchers had predicted. A positive effect exists for employee turnover and sales in the intervention stores. Based on the process analysis, the team processes unfolded successfully and the team members considered the process analysis helpful and beneficial professional development experience [8].

The findings from the Action Team intervention may not show generalizable to corporate workplaces, where team problem solving is often an integral part of 
everyday operations [8]. The healthy work organization model could easily serve as a framework for different types of interventions tailored to the unique conditions of a particular worksite. Both the model analysis and the intervention study affirmed the validity of the model. The advantages of naturalistic research included the effects of the intervention amidst turbulent work conditions [8]. The most striking finding is that the employees in the intervention stores did not experience the increases in stress that typically accompany organizational change.

\subsection{Wellness Programs}

The term wellness is more than a program offering physical exercise, smoking cessation, or weight management [10]. Workplace wellness programs can foster a wellness culture characterized by employee engagement and social networks that encourage organizational citizenship, trust, high performance, and productivity [8]. The benefits are evident at the individual, group, and organizational level in the form of good health, superior performance, and profitability [10].

Wellness programs can include several different forms [11]. Wellness programs are describable as primary prevention. Unlike EAPs, Wellness programs have no negative connotation. Management may list wellness programs, EAPs, and stress management programs under the HRM umbrella. Wellness programs range in scope from rudimentary to extremely comprehensive [8].

Willis North America team leaders' conduct annual surveys of employee health and productivity. Wellness was a prominent issue for the 2010 and 2011 surveys, which include employee engagement and work-life balance as well [8]. Willis team leaders characterized wellness programs as basic, intermediate, and comprehensive. A basic program generally just beginning, has a small (or no) budget, and offers limited activities for example, lunch-and-learn seminars and health fairs. Intermediate programs include wellness committees or internal program coordinators. These programs augment the features of a basic program with offerings for example, onsite screenings, health coaching, or wellness web portals [12]. Institutional leaders have a formal budget and offer some incentives for participation. Comprehensive programs include intermediate programs by offering targeted behavioral change programs, along with incentives. The most comprehensive programs include spouses, program monitor data, and formal evaluations of their impact [3].

The number of organizations that either had a wellness program in place or planned to offer one in the future increased from 2010 to 2011 [8]. Most of the wellness programs came under basic program classification. Firms with 500 or more employees were more likely to include an intermediate or comprehensive wellness program [8].

In descending order, the ten most common wellness components in 2011 were flu shots (82\%), EAPs (82\%), and flyers, posters, and newsletters encouraging healthy behaviors sixty three percent [8]. Others are Lunch ' $N$ Learn or educational seminars (55\%), physical activity programs (53\%), disease management 
(51\%), and health fairs (49\%). The rest is health coaching (onsite, online, or by phone; 49\%), smoking cessation programs (49\%), and weight management programs forty nine percent [8].

Evidence existed in the various wellness program components that the term wellness has different meanings [8]. The three big programs typically associated with the concept of wellness are physical activity, smoking cessation, and weight management. The survey results revealed some unusual program components. Worthy of consideration are peer support groups $(8 \%)$, training managers and supervisors who promote wellness program goals (8\%), onsite pharmacies (7\%), and provider quality measurements for example, Leapfrog or Health-grades five percent [8].

The 2010 survey includes issues related to the implementation of a workplace wellness program [8]. The main reason for establishing a wellness program was trending in healthcare costs, cited by $78 \%$ of the respondents. According to Avey et al. (2009), this figure was ninety-two percent. The second most prevalent reason was corporate goals and objectives (39\%), followed by costs associated with chronic conditions (34\%). Approximately $38 \%$ of the programs extended benefits to spouses. The main barriers to implementing a wellness program were insufficient time and staff resources (44\%) and budget constraints (43\%) [8]. Lack of interest by employees or management was less common $(21 \%$ and $11 \%$, respectively). Many employees do not participate in wellness programs [13].

Wellness programs offered by management often fail because they do not reflect the personal preferences of the employees [7]. An excellent way to overcome that obstacle is to involve the employees in designing the program [14]. Strategies to encourage active participation in the programs, offer the employees a sense of ownership, which is inherently empowering [7]. A program promoted among employee social networks and endorsed by executive management has the best chance of being successful [14]. In effect, word-of-mouth advertising is the most effective marketing technique [14].

Wellness programs date back to the 1970s when business leaders began to analyze employee productivity and devised a strategy to increase employee efficiency [15]. During the 1970s, the Worksite Health Promotion Movement (WHP) began linking employee health with various work-related factors [15]. In addition to providing health insurance, business leaders began to foster employee health in the workplace [2]. The 1970s Occupational Safety and Health Movement, which also advocated analyses of employee productivity, assisted the movement [15].

Throughout the 1980s and 1990s, people in the United States became more interested in health as a lifestyle issue, and this led to increasing awareness of obesity problems and other related chronic illnesses [15]. By the start of the 2000s, many leaders in firms were offering different models of wellness programs to employees [15]. To increase employee participation in workplace wellness programs, employers are trying out various types of incentives. Rewarding 
employees is more important than coercing them to participate in wellness programs [13]. Numerous types of incentives exist, but gift cards and cash cards are popular [8] [13]. Some managers offer programs to employees at lower premiums on their medical plans and others offer lower deductibles. Additional incentives include merchandise, points toward rewards, and contributions to health care accounts. Notably, the most effective incentives are those related to health and insurance costs [16].

While evidence abounds that incentives boost employee participation in wellness programs and promote adherence to certain behaviors (for example, physical exercise or smoking cessation), evidence is scant regarding incentives that create enduring behavior change [13]. Evidence exist that employees are less likely to sustain behaviors encouraged by incentive programs. Howard attributed the evidence to the observation that extrinsic rewards drove the initial behavior change. The argument was that to help people maintain the desired behaviors, staff members should emphasize the intrinsic benefits of the activity. For example, the benefits of regular physical exercise including feeling more energetic, sleeping better, maintaining a healthy weight, and feeling and looking better. The emphasis on intrinsic rewards is consistent with Maslow's (1954) theory.

Positive and negative sides exist in the use of incentives, wellness programs, and workplace health. The programs include determinable advantages and disadvantages [13]. First, on the positive side of the outcome-based incentives, directly linking incentive rewards to desired health outcomes can motivate employees to become and stay healthy. Second, incentives offered by management may spur employees to change unhealthy behaviors. Third, policies offered by management may prove rewarding healthy behaviors or outcomes may attract healthier individuals as prospective employees. Fourth, rewards for wellness participation by management may stimulate a shift toward a wellness culture [13].

Findings from behavioral economics suggest that rewarding employees for changing behavior or engaging in beneficial activities are more effective than tying rewards to outcomes [13]. First, constraints offered by management resulting from administrative provisions intended to protect employees against discrimination may work against outcomes-based incentives. The employees who stand to gain the most from the program may opt-out instead. Second, the policy provided by management may benefit employees who might otherwise make healthy choices. The most vulnerable individuals may ultimately pay more, as they attain less positive outcomes [13]. Members of ethnic minorities and older workers, less educated, and have lower incomes stand to gain less from the programs. Third, some people in poor health cannot try to reach a designated outcome in time for a reward. Fourth, some individuals might end up paying higher premiums. Behaviors and outcomes that are not fully under human control could lead to higher premiums [17].

Disadvantages may seem to outweigh the advantages, and employers tend to move away from incentives based on participation and adopting incentive pro- 
grams based on health outcomes [13]. The number of organizations offering rewards based on outcomes for weight or cholesterol level doubled in 2011 and one-third of the respondents said they planned to adopt an outcome-based incentive strategy [13]. In 2010, only a scant $6 \%$ of employers had that type of incentive program [13]. If the disadvantages appear to outweigh the advantages numerically, the benefits of outcome-based incentives will have a more direct impact on the health-related costs of the organization and the organizational culture.

\subsection{Job Satisfaction}

Salancik and Pfeffer (1977) [18] developed a need-satisfaction model of job characteristics, needs, attitudes, and behaviors to explain the relationship between job satisfaction and job motivation. The theory based on the premise that leaders inspire followers to change their expectations, perceptions, and motivations to work toward common goals. Salancik and Pfeffer (1977) identified the following variables for predicting the values for the construct, job satisfaction, as measured by the instrument: 1) wellness-program participation (WP), 2) gender (GEN), 3) years of teaching experience ( $\mathrm{YoE}$ ), and 4) age ( $A G E$ ). Applying their job satisfaction model to the current study, the authors expected the dependent variables measured by the job satisfaction survey (JSS) to influence or explain employee job satisfaction because understanding factors for example, human needs are critical to the implementation of employee satisfaction programs [19].

Sadri and Bowen (2011) described the relationship between motivation and satisfaction, positing that workers require a range of motivators to remain engaged in their work. Employers are in a continuing struggle to satisfy their employees' evolving needs, through extrinsic and financial means also through intrinsic and psychological means [19]. Sadri and Bowen (2011) explained how company leaders try to balance monetary (extrinsic) and nonmonetary (intrinsic) incentives. Leaders of many organizations use diverse motivators ranging from competitive monetary compensation and health insurance packages [19]. Some company leaders use concierge services and designated nap times to motivate employees [19].

\subsection{Job Satisfaction in Higher Education}

A research study on job satisfaction in higher education contained a consideration of institutional, work, and individual determinants of faculty at a university [20]. The research revealed that faculty members have a high level of satisfaction when they perceive that other employees respect their work. Job satisfaction also had a connection with members' perceptions of their compensation. Women were less satisfied, although the tenured reported higher satisfaction. Bozeman and Gaughan (2011) [21] discovered that affiliations to university and industry centers did not predict job satisfaction. In a research study focusing on teacher job satisfaction in higher education, 1430 teachers participated and responded to 
a questionnaire [20]. Participant responses indicated certain differences in multiple factors. The factors included work gender relations, teachers' characteristics, self-efficacy, job stress, and job satisfaction experience.

The study of presenteeism is a recent phenomenon [22]. Absenteeism was the primary measure of lost productivity. Presenteeism is the problem of employees physically present, but are functionally absent at work. Physical or psychological health conditions are responsible for low functionality [22]. Organizational decision-makers have recognized presenteeism as a threat to organizational performance and productivity. Presenteeism diminishes individual productivity by at least one-third. Unlike absenteeism, which might appear obvious, presenteeism can go unnoticed and creates a negative impact [22]. Estimating the cost of presenteeism is complicated, but researchers have been examining the cost and impact of presenteeism on organizational productivity. Activities in this study include exploring the relationship between presenteeism, job satisfaction, and wellness programs.

Considering the escalating costs related to health conditions, increasing numbers of organizational leaders are investing in health promotion and wellness programs. The Willis North America Health and Productivity Survey (2011) revealed that more than $60 \%$ of the 1598 organizations surveyed had some wellness programs. Exit interviews conducted by Nelnet revealed that employees are leaving organizations because they would mostly miss the wellness program [8]. Data from organizations that have evaluated their wellness programs show Return on Investment. Many businesses incidentally do not evaluate ROI. The main reason cited is inadequate resources. Additional reasons include confusion on how to measure outcomes and the belief that ROI is not measurable or that measuring ROI is not worth the effort and cost [8].

Cost is an obstacle to establishing a company wellness program [8]. The costs arising from an unhealthy workforce raise the question of whether businesses can afford not to have some health promotion or wellness program. A holistic perspective of health and the concept of a healthy work organization lead to programs promoting employee health and productivity. These programs occupy a broad spectrum including work redesign and empowerment strategies, training and development opportunities, employee assistance programs (EAPs), and wellness, health promotion, and stress management programs [23]. Green buildings, designed to improve indoor environmental quality, boost productivity and reduce absenteeism and presenteeism related to asthma, respiratory allergies, stress, and depression [8]. Numerous strategies exist that business leaders can apply to improve employees' physical and psychosocial health and, by extension, organizational health and productivity.

Stress management programs fall into categories for example, primary, secondary, and tertiary prevention, and intervention [24]. Programs designed to alleviate stress fall under the heading of primary prevention and include organizational strategies. For example, job redesign, employee engagement and empo- 
werment programs, and coworker support groups. Stress management programs or interventions are usually associated with secondary prevention programs, which are programmatic creations for decreasing the severity of stress symptoms before they have a negative impact on physical or psychological health [24].

Employee Assistance Programs (EAP) are tertiary programs because leaders use them for employees with confidential counseling and therapy [24]. Management provides employee assistance programs more aligned with primary and secondary prevention for example, helping workers find childcare, accountants, and wedding planners. Some offer financial counseling, management training, and educational seminars. Given the association with mental health problems, some stigma attaches to seeking services from EAPs. Human resource (HR) professionals are working to change the image of EAPs to encourage more employees to make use of this valuable resource [24].

\subsection{Maslow's Hierarchy of Needs Theory}

The hierarchy of needs is part of Taylor's legacy for at least half of the $20^{\text {th }}$ century; include extrinsic rewards perceived as the way to motivate employees [25]. Originally developed in the 1950s, classic theory includes the powerful role of intrinsic motivation [25]. Maslow's theory has included numerous theoretical and empirical explorations of motivation [26]. The issue of whether Maslow intended his hierarchy of needs to serve as a model or whether he only meant to explain and clarify human motivation has been a subject of much dispute [25]. In response to critics of the hierarchical structure, Maslow acknowledged that human needs do not necessarily unfold in a rigid, linear fashion. The pyramidal design is one of the attractions for researchers who have chosen Maslow's theory as a theoretical framework.

Physiological needs, the essential needs for survival, are at the lowest level of the hierarchy [25]. After meeting these needs, the person advances to the next level of safety and security. Freedom from stress and anxiety probably falls under physiological needs. As the literature reviewed for this chapter illustrates, stress is ubiquitous in modern society. The concept of stress falls along a continuum that implies the necessity to understand that individual perceptions vary regarding acceptable levels of stress [26]. Lazarus (1989) indicated stress appraisal is central to transactional theory of stress and coping. Lazarus (1989) emphasized the dynamic and individual nature of stress perceptions in describing occupational stress and its personal and organizational ramifications.

The eradication of workplace stress cannot occur by organizations, and even if possible, doing so would not prove desirable. Individuals differ tremendously in their perceptions of stress, and conditions that reduce stress for some employees may intensify for others [27]. Despite the negative connotation attached to the word stress, it can also enhance and motivate [26]. Creating an empowering workplace decreases stress and burnout and boosts performance and job satisfaction [7]. Financial concerns are a major source of stress for many employees, 
and financial counseling and education can prove effective in addressing this source of stress and improving performance and productivity [24].

The need for social and belongingness occupy the third level of the hierarchy [25]. Collaborative workplace relationships are equally pertinent to the next level of the hierarchy fulfilling the desires to feel confident, self-assured, competent, and respected [25]. The next level of the hierarchy consists of ego, status, and self-esteem needs. A healthy work organization addresses all of these needs [4].

The final human need in Maslow's (1954) hierarchy is the need for self-actualization. Maslow was aware that human beings meet all the lower needs, and they often feel discontented. The need for self-actualization arises from the desire to fulfill one's potential to the utmost [25]. Spreitzer and Porath (2012) used the term thriving to refer to a workforce when workers experience satisfaction, productiveness, and engagement in creating the future for the company and stakeholders. Thriving employees are highly energized and adept at avoiding burnout.

Two key qualities or characteristics of thriving employees are vitality and learning [7]. Employees who possess vitality energize others around them with their commitment and passion. Learning includes the growth of one attains by acquiring new knowledge and skills. Training new knowledge and skills were the focus of a research study that relied on Maslow's theory to frame their case that technology and training were are key factors in maintaining a motivated and dedicated healthcare workforce [26].

Some perspectives of technology hold the promise of fulfilling self-actualization needs to an unprecedented degree [28]. Training is the pivotal factor in exploiting the tremendous potential of new technologies for personal and organizational growth. Even apart from technology, providing employees with learning opportunities that foster personal growth can decrease burnout and benefit both the employee and the organization [28]. Social media includes a forum for online communities where employees share information on topics related to health, medical decisions, and wellness [29].

The fulfillment of each of the needs, in particular, self-actualization, varies substantially from one individual to the next [25]. Maslow's hierarchy is usually construed to mean that needs on lower levels of the hierarchy must be met before one aspires to meet the needs of the next level. Individual differences, however, influence how people value the different levels of needs [25]. For example; some people have a greater need for self-esteem than for love and belonging. For some creative individuals, the need for self-actualization takes precedence over all of the lower needs. In climates of economic uncertainty, the lower level needs represent a major source of stress for many employees [24]. Scholars could argue that stress undermines the quest for self-actualization. Uncertain satisfaction of lower-level needs often contributes to the stress by exerting a negative impact on work performance. Stress may also intensify the need for esteem and belonging.

An Indian Human Resource Management theorist [30], Mahesh (1993) created 
a model combining Maslow's hierarchy with principles from Hindu philosophy. The highest needs levels of his East-West model are aharya (self-esteem) and sahaja (self-actualization). The theorist added that an individual achieves a quality of performance based on intrinsic motivation for self-actualization through the achievement of mastery and self-esteem in the chosen field of endeavor. From this perspective, which exemplifies excellent HRM practice, an individual's personal and professional growth and organizational performance intertwine.

Organizational decision-makers cannot entirely eradicate workplace stress, and even if they could, doing so would not prove desirable. Individuals differ tremendously in their perceptions of stress, and conditions that reduce stress for some employees may intensify it for others [27]. Despite the negative connotation attached to the word stress, it can also be enhancing and motivational [26]. Creating an empowering workplace decreases stress and burnout and boosts performance and job satisfaction [7]. Financial concerns are a major source of stress for many employees, and financial counseling and education can prove effective in addressing this source of stress and improving performance and productivity [24].

The need for social and belongingness occupy the third level of the hierarchy [25]. Collaborative workplace relationships are equally pertinent to the next level of the hierarchy fulfilling the desires to feel confident, self-assured, competent, and respected [25]. The next level of the hierarchy consists of ego, status, and self-esteem needs. A healthy work organization must include all of these needs [4].

The final, uniquely human need in Maslow's (1954) hierarchy is the need for self-actualization. Maslow was aware that even when human beings meet all the lower needs, human beings often feel discontented. The need for self-actualization arises from the desire to fulfill one's potential to the utmost [25]. Spreitzer and Porath (2012) described the term thriving to refer to a workforce where workers experience satisfaction, productiveness, and engage in creating the future for the company and its stakeholders. Thriving employees are energized and adept at avoiding burnout.

Two key qualities characteristic of thriving employees are vitality and learning [7]. Employees who possess vitality energize others around them with their commitment and passion. Learning refers to the growth of one attains by acquiring new knowledge and skills. Providing knowledge and training new skills was the focus of a research study that relied on Maslow's theory to frame their case that technology and training were key factors in maintaining a motivated and dedicated healthcare workforce [31]. Although healthcare, an industry undergoing massive upheaval was the primary focus, Benson and Dundis (2012) recognized that similar changes are occurring across industry sectors.

Some perspectives of technology hold the promise of fulfilling self-actualization needs to an unprecedented degree [31]. Training is the pivotal factor in exploiting the tremendous potential of new technologies for personal and organizational growth. Even apart from technology, providing employees with learning op- 
portunities that foster personal growth can decrease burnout and benefit both the employee and the organization [28]. Management, through technology, provides an effective way for delivering educational programs ranging from management training to stress management and psycho-educational interventions [29] [32]. Social media include a forum for online communities where employees share information on topics related to health, medical decisions, and wellness [29].

The fulfillment of each of the needs, in particular, self-actualization, would vary substantially from one individual to the next [25]. Maslow's hierarchy is usually construed to indicate that needs on lower levels of the hierarchy must be met before one aspires to meet the needs of the next level. Individual differences were clear in how people valued the different levels of needs. For example, some people have a greater need for self-esteem than for love and belonging. For some creative individuals, the need for self-actualization takes precedence over all of the lower needs. In climates of economic uncertainty, the lower level needs represent a major source of stress for many employees [24]. Scholars could argue that stress undermines the quest for self-actualization. Uncertain satisfaction of lower-level needs often contributes to the stress by exerting a negative impact on work performance. Stress may also intensify the need for esteem and belonging [24] [25].

An Indian HRM theorist created a model combining Maslow's hierarchy with principles from Hindu philosophy. The highest need levels of his East-West model are aharya (self-esteem) and sahaja (self-actualization) [25]. The theorist added that an individual achieves a quality of performance based on intrinsic motivation for self-actualization through the achievement of mastery and self-esteem in the chosen field of endeavor. From this perspective, which exemplifies excellent HRM practice, an individual's personal and professional growth and organizational performance intertwine [25].

Published in 2000, The Maslow Business Reader is a collection of articles on employee motivation in the business and organizational environment by Maslow and several authors in the management field [31]. The basic needs level involves satisfaction with pay. Beyond the economic need for remuneration that satisfies basic survival needs, Maslow proposed that employees receiving fair compensation would not devote time to contemplate their salaries, whereas individuals whose compensation appeared unfair could spend-time ruminating over the inequity to the detriment of their work [24].

\section{Research Question and Hypothesis}

The overarching research question was as follows: What, if any, relationships exist between the 1) wellness program full-time or part-time faculty participation status (WP), 2) gender (GEN), 3) years of teaching experience (YoE), 4) age (AGE), 5) job satisfaction.

The following sub research questions (SRQs) are also relevant for addressing the study's purpose: 
SRQ 1. What, if any relationship exist between employer-sponsored wellness program participation and job satisfaction?

SRQ 2. What, if any relationship exist among employer-sponsored wellness program participation, gender, and job satisfaction?

SRQ 3. What, if any relationship exist among employer-sponsored wellness program participation, age, and job satisfaction?

SRQ 4. What, if any relationship exist among employer-sponsored wellness program participation, years of job experience, and job satisfaction?

\section{Hypotheses}

H10: There is no relationship between employer-sponsored wellness program participation and job satisfaction.

$H 1_{\mathrm{a}}$ : There is a relationship between the wellness program participation and job satisfaction.

H20: There is no relationship between wellness program participation, gender, and job satisfaction.

$H 2_{\mathrm{a}}$ : There is a relationship between wellness program participation, gender, and job satisfaction.

$H 3_{0}$ : There is no relationship between the wellness program participation, years of experience at the job, and job satisfaction.

$H 3_{\mathrm{a}}$ : There is a relationship between the wellness program participation, years of experience at the job, and job satisfaction.

$\mathrm{H4}_{0}$ : There is no relationship between wellness program participation, age, and job satisfaction.

$H 4_{a}$ : There is a relationship between wellness program participation, age, and job satisfaction.

\section{Methodology}

\section{Measuring Job Satisfaction}

The instrument for the study included the Job Satisfaction Survey (JSS) instrument. I chose the JSS instrument because of its appropriateness in assessing overall job satisfaction of employees [33]. An instrument was used to enable the measuring associations among variables involving individuals within for-profit colleges and universities.

Concepts measured by the instrument. The Job Satisfaction Survey is an instrument for measuring job satisfaction in public and private organizations [33]. Organizations for the study included for-profit colleges and universities. The 36-item scale assesses nine components of job satisfaction: pay, promotion, supervision, benefits, contingent rewards, operating procedures, coworkers, nature of work, and communication. The scale also includes a score for overall satisfaction [33].

Adiele and Abraham (2013) indicated that the concept of job satisfaction with the establishment of different measures indicating employees' satisfaction. Job satisfaction includes people's perceptions about the workplace environment and 
psychological as well as physical needs that satisfy employees [34]. Diverse studies, experiments, and concepts included insights into job satisfaction. Understanding the ways of measuring job satisfaction is imperative. An exploration of the correlation between employee wellness programs and job satisfaction in higher education would require understanding [34].

Adiele and Abraham (2013) developed tools that can help to evaluate the degree of happiness or dissatisfaction among employees in different workplaces. Certain tools of measuring job satisfaction are preferable over others, although job satisfaction measurement may extend as far as employers' resources, knowledge, and imagination warrant [10]. Adiele and Abraham indicated the use of diverse methods to determine the degrees of job contentment. Job Descriptive Index (JDI) is one of the tools. Another tool is the Measure of Job Satisfaction (MJS). Business leaders use the Job in General Scale (JIG). Employers use the Minnesota Survey Questionnaire (MSQ) and the Job Satisfaction Survey (JSS). Diverse corporate leaders and researchers use the Andrew and Whitney Job Satisfaction Questionnaire, among others [10].

The JDI is one of the most used job satisfaction questionnaires [35]. The questionnaire includes the measures of job satisfaction using five factors, pay, promotional opportunities, coworkers, supervision, and regular work. Researchers have employed the JDI instrument to carry out studies on job satisfaction among employees in different disciplines, including higher education [35] [36]. Scholars have used the Job Descriptive Index instrument in diverse research studies relating to job satisfaction [36].

The JIG is another popular instrument for measuring job satisfaction [35]. The tool initially pertained to the participant's considerations of job satisfaction based on generalized opinions or overall terms. The JIG was an enhancement to the JDI instrument. The JIG instrument included overall satisfaction rather than individual facets of job satisfaction, which constitutes the focus of JDI [35].

The MSQ instrument also measures content as well as context components of job contentment [34]. Management can use MSQ to evaluate job contentment because of different aspects of work as well as the work environment. The instrument is versatile because it includes both long- and short-form surveys.

The MJS is a multidimensional instrument for measuring job satisfaction. MJS includes 38 items and stem queries, that is, How content are you with this feature of your profession? In the instrument, participants indicate their level of job contentment based on a five-point Likert scale. The scale usually ranges from extremely satisfied to extremely dissatisfied and includes a nonaligned response choice [37]. Based on the features of the instruments, the JSS appears an appropriate instrument for the study.

\section{RESEARCH METHOD}

The quantitative research methodology was appropriate for the study. The design of the study was correlational. Diverse types of quantitative designs are available and the choice of design rests on how a researcher interacts with par- 
ticipants [38]. The appropriate category of techniques depends on the data needed to answer the research question.

Using surveys in quantitative research studies include a meaningful description of attitudes, trends, and opinions by evaluating the factors related to a relevant sample of the target population [39]. The survey instrument is the tool to reveal the behavior of each variable in the study. A generalization of the findings from a sample to the population is an objective for quantitative designs [40]. A quantitative online survey was appropriate for the current study, as the authors were interested in collecting data from a large pool of prospective participants. One hundred and three participants were included in this study.

\section{FINDINGS OF THIS STUDY}

Using frequency distributions, the authors summarized the participants' responses regarding their participation in their college and university wellness programs. Table 1 presents the results of this analysis.

The majority of the respondents $(N=57,66.0 \%)$ were not participating in their college and university wellness programs. The remaining 35 (34\%) faculty members indicated that they were participating in these programs. The gender and age of the participants receive cross-tabulation by their participation in their college and university's wellness programs. The results of the analyses are in Table 2.

Of the five (4.9\%) participants who were between 21 and 29 years of age, $3(8.6 \%)$

Table 1. Frequency distributions-participation in wellness programs.

\begin{tabular}{ccc}
\hline Participation in Wellness Program & Number & Percent \\
\hline Yes & 46 & 46.0 \\
No & 57 & 66.0 \\
Total & 103 & 100.0 \\
\hline
\end{tabular}

Table 2. Cross tabulations-age and gender by participation in wellness programs.

\begin{tabular}{|c|c|c|c|c|c|c|}
\hline \multirow{3}{*}{ Age and Gender } & \multicolumn{4}{|c|}{ Participation in Wellness Programs } & \multirow{2}{*}{\multicolumn{2}{|c|}{ Total }} \\
\hline & \multicolumn{2}{|c|}{ Yes } & \multicolumn{2}{|c|}{ No } & & \\
\hline & $N$ & $\%$ & $N$ & $\%$ & $N$ & $\%$ \\
\hline \multicolumn{7}{|l|}{ Age } \\
\hline 21 to 29 & 3 & 8.6 & 2 & 2.9 & 5 & 4.9 \\
\hline 30 to 39 & 10 & 28.5 & 9 & 13.2 & 19 & 18.4 \\
\hline 40 to 49 & 5 & 14.3 & 23 & 33.9 & 28 & 27.2 \\
\hline 50 to 59 & 12 & 34.3 & 20 & 29.4 & 32 & 31.1 \\
\hline 60 and over & 5 & 14.3 & 14 & 20.6 & 19 & 18.4 \\
\hline Total & 35 & 100.0 & 68 & 100.0 & 103 & 100.0 \\
\hline \multicolumn{7}{|l|}{ Gender } \\
\hline Male & 17 & 48.6 & 25 & 36.8 & 42 & 40.8 \\
\hline Female & 18 & 51.4 & 43 & 63.2 & 61 & 59.2 \\
\hline Total & 35 & 100.0 & 68 & 100.0 & 103 & 100.0 \\
\hline
\end{tabular}


were participating in wellness programs, and $2(2.9 \%)$ were not participating in these programs. Nineteen (18.4\%) of the participants were between 30 and 39 years of age, with $10(28.5 \%)$ participants in this age group indicating they were participating in their college/university wellness programs and 9 (13.2\%) were not participating in these programs. Five (14.3\%) of participants who were between 40 and 49 years of age were participating in wellness programs and 23 (33.9\%) of participants in this age group were not participating. Thirty-two (31.1\%) of the participants were between 50 and 59 years of age. From the number, $12(34.3 \%)$ were participating in their college and university's wellness programs and 20 (29.4\%) were not participating. Among the participants who were 60 years of age or older $(N=19,18.4 \%), 5(14.3 \%)$ were participating in their college and university's wellness programs and $14(20.6 \%)$ were not participating in these programs.

The majority of the participants $(n=61,59.2 \%)$ were female. The number included 18 (51.4\%) females who were participating in the wellness programs at their colleges and universities' and $25(36.8 \%)$ were not participating in these programs. Seventeen (48.6\%) participants in wellness programs were male. Twenty-five (36.8\%) of the male faculty members were not participating in these programs.

The participants provided their professional characteristics in the survey. The responses of the participants receive cross-tabulation by participation in their college and university's wellness programs. Table 3 presents the results of this analysis.

Of the $36(35.0 \%)$ participants who had worked from 0 to 5 years as a faculty

Table 3. Cross tabulations-professional characteristics by participation in wellness programs.

\begin{tabular}{|c|c|c|c|c|c|c|}
\hline \multirow{3}{*}{ Professional Characteristics } & \multicolumn{4}{|c|}{ Participation in Wellness Programs } & \multirow{2}{*}{\multicolumn{2}{|c|}{ Total }} \\
\hline & \multicolumn{2}{|c|}{ Yes } & \multicolumn{2}{|c|}{ No } & & \\
\hline & $N$ & $\%$ & $N$ & $\%$ & $N$ & $\%$ \\
\hline \multicolumn{7}{|l|}{ Years as a faculty member } \\
\hline 0 to 5 years & 13 & 37.2 & 23 & 33.8 & 36 & 35.0 \\
\hline 6 to 10 years & 7 & 20.0 & 20 & 29.4 & 27 & 26.2 \\
\hline 11 to 15 years & 4 & 11.4 & 10 & 14.7 & 14 & 13.6 \\
\hline 15 years or longer & 11 & 31.4 & 15 & 22.1 & 26 & 25.2 \\
\hline Total & 35 & 100.0 & 68 & 100.0 & 103 & 100.0 \\
\hline \multicolumn{7}{|l|}{ Years in a wellness program } \\
\hline NA & 4 & 11.8 & 38 & 100.0 & 42 & 58.3 \\
\hline 1 to 2 years & 9 & 26.5 & 0 & 0.0 & 9 & 12.5 \\
\hline 3 to 5 years & 12 & 35.2 & 0 & 0.0 & 12 & 16.7 \\
\hline Five years of more & 9 & 26.5 & 0 & 0.0 & 9 & 12.5 \\
\hline Total & 34 & 100.0 & 38 & 100.0 & 72 & 100.0 \\
\hline Missing & 1 & & 30 & & & \\
\hline
\end{tabular}


member, $13(37.2 \%)$ were participating in the wellness program at their college/university, and 23 (33.8\%) were not participating in these programs. Twenty-seven $(26.2 \%)$ of the participants had from 5 to 10 years as a faculty member. Of this number, 7 (20.0\%) were participating in wellness programs and 20 (29.4\%) were not participating in these programs. Four (11.4\%) of faculty members who had from 11 - 15 years' experience were participating in their college/universities' wellness programs, with 10 (14.7\%) participants with this length of experience were not participating in these programs. Of the $26(25.2 \%)$ faculty members who had 15 years or more experience, 11 (31.4\%) were participating in the wellness programs at their college/universities and 15 (22.1\%) were not participating in these programs.

The participants, when asked the number of years in which they had participated in the wellness programs, $4(11.8 \%)$ in the group that indicated they had participated responded not applicable (na). Twenty-three (33.8\%) in the group who indicated they had not participated indicated na. Nine (26.5\%) of the participants who had participated in the wellness programs reported they participated for 1 to 2 years, with 9 (26.5\%) reporting they had participated for 3 to 5 years, and $9(26.5 \%)$ indicating they had participated for five years or more. One person in the group that had participated in the wellness programs did not provide a response to this question and 30 who were in the group that had not participated did not answer this question.

After recoding the values on the selected items on the survey, the authors obtained descriptive statistics to provide baseline information regarding the levels of job satisfaction between the faculty members who were participating in the wellness programs at their colleges and universities and those who were not participating in these programs. Table 4 presents the results of this analysis.

The mean score for job satisfaction for faculty members who participated in the wellness programs was 3.80 ( $\mathrm{SD}=0.52$ ), with a median of 3.69. The range of scores was from 3.11 to 5.42 . Among the faculty members who did not participate in the wellness programs, the mean score was $3.62(\mathrm{SD}=0.32)$, with a median of 3.62. The actual scores on this subscale could range from 2.78 to 4.64. Possible scores on this scale could range from 1.00 to 6.00 , with higher scores indicating greater job satisfaction.

The authors used a linear regression analysis to determine if a statistically significant relationship existed between participation in a wellness program and job satisfaction. The results of this analysis are in Table 5.

Table 4. Descriptive statistics-job satisfaction by group membership.

\begin{tabular}{ccccccc}
\hline Group & Number & Mean & SD & Median & \multicolumn{2}{c}{ Range } \\
\cline { 6 - 7 } & & & & & Minimum & Maximum \\
\hline $\begin{array}{c}\text { Participated in wellness program } \\
\begin{array}{c}\text { Did not participate in wellness } \\
\text { programs }\end{array}\end{array}$ & 68 & 3.80 & .52 & 3.69 & 3.11 & 5.42 \\
\hline
\end{tabular}


Participation in the wellness program was accounting for $5 \%$ of the variance in job satisfaction, $F(1,101)=5.01, p=0.027$. The negative relationship between job satisfaction and participation in the employer-sponsored wellness program $(\beta=-0.22, t=-2.24, p=0.027)$ indicated that faculty who were not participating in the wellness program tended to have higher levels of job satisfaction. This finding provided support to reject the null hypothesis that job satisfaction related to participation in employer-sponsored wellness programs.

SRQ 2. What relationship, if any, is there between the employer-sponsored wellness program participation status, gender, and job satisfaction?

H20: There is no relationship between the employer-sponsored wellness program participation status, gender, and job satisfaction (JS).

$H 2_{\mathrm{a}}$ : There is a relationship between the employer-sponsored wellness program participation status, gender, and job satisfaction (JS).

Multiple linear regression analysis used to determine if participation in an employer-sponsored wellness program and gender could lead to the prediction of job satisfaction. The results of this analysis presented in Table 6 .

Together, participation in an employer-sponsored wellness program and gender of the faculty member were accounting for $11 \%$ of the variance in job satisfaction, $F(2,100)=6.29, p=0.003$. The negative relationship between participation in the wellness program and job satisfaction $(\beta=-0.19, t=-1.98, p=$ 0.050 ) provided support that faculty who did not participate in the wellness program were more likely to have higher levels of job satisfaction. The relationship

Table 5. Linear regression analysis-job satisfaction and participation in employer-sponsored wellness programs.

\begin{tabular}{cccccccc}
\hline \multicolumn{2}{c}{ Predictor } & Constant & $b$-Weight & $\beta$-Weight & $R^{2}$ & $t$ & Sig \\
\hline Participate in wellness program & 3.99 & -.19 & -.22 & 0.05 & -2.24 & 0.027 \\
& & & & & & & \\
Multiple $R$ & 0.227 & & & & & & \\
Multiple $R^{2}$ & 0.057 & & & & & & \\
$F$ Ratio & 5.017 & & & & & & \\
DF & 1101.027 & & & & & & \\
Sig & & & & & & & \\
\end{tabular}

Table 6. Multiple linear regression analysis-job satisfaction, participation in employer-sponsored wellness programs, and gender.

\begin{tabular}{|c|c|c|c|c|c|c|c|}
\hline \multicolumn{2}{|c|}{ Predictor } & Constant & $b$-Weight & $\beta$-Weight & $R^{2}$ & $t$ & Sig \\
\hline \multirow{2}{*}{\multicolumn{2}{|c|}{$\begin{array}{l}\text { Participate in wellness program } \\
\text { Gender }\end{array}$}} & \multirow{2}{*}{4.29} & -0.16 & -0.19 & \multirow{2}{*}{0.11} & -1.98 & 0.050 \\
\hline & & & -0.21 & -0.26 & & -2.70 & 0.008 \\
\hline Multiple $R$ & 0.337 & & & & & & \\
\hline Multiple $R^{2}$ & 0.117 & & & & & & \\
\hline$F$ Ratio & 6.297 & & & & & & \\
\hline$D F$ & 2.1007 & & & & & & \\
\hline Sig & 0.003 & & & & & & \\
\hline
\end{tabular}


between gender and job satisfaction $(\beta=-0.26, t=-2.70, p=0.008)$ was in a negative direction, indicating that females were more likely than males to have higher levels of job satisfaction. The results of this analysis provided evidence to reject the null hypothesis of no relationship between job satisfaction and participation in employer-sponsored wellness programs and gender.

SRQ 3. What relationship, if any, is there between the employer-sponsored wellness program participation status, years of experience at the job, and job satisfaction (JS)?

$H 3_{0}$ : There is no relationship between the employer-sponsored wellness program participation status, years of experience at the job, and job satisfaction (JS).

$H 3_{a}$ : There is a relationship between the employer-sponsored wellness program participation status, years of experience at the job, and job satisfaction (JS).

Multiple linear regression analyses used to determine if job satisfaction (dependent variable) could predicate by participation in the employer-sponsored wellness program and years of experience on the job. As years of experience was an ordinal variable, the categories were dummy coded for the analysis. Table 7 presents the results of this analysis.

Eleven percent of the variance in job satisfaction was explained by participation in employer-sponsored wellness programs and years of experience at their institutions, $F(4,98)=3.02, p=0.021)$. The negative relationship between participation in employer-sponsored wellness programs and job satisfaction ( $\beta=$ $-0.23, t=-2.42, p=0.018)$ provided evidence that faculty who did not participate in the wellness programs tended to have higher levels of job satisfaction. A positive relationship was found between being a faculty member for 11 to 15 years and job satisfaction $(\beta=0.32, t=2.58, p=0.012)$, indicating that faculty who had been employed between 11 and 15 years were more likely to have higher levels of job satisfaction. The other two variables were measuring 6 to 10 years of experience, and more than 15 years of experience not significantly related to job satisfaction.

Based on this finding, the null hypothesis that job satisfaction related to

Table 7. Multiple linear regression analysis-job satisfaction, participation in employer-sponsored wellness programs, and years of experience.

\begin{tabular}{|c|c|c|c|c|c|c|c|}
\hline \multicolumn{2}{|c|}{ Predictor } & Constant & $b$-Weight & $\beta$-Weight & $R^{2}$ & $t$ & Sig \\
\hline \multicolumn{2}{|c|}{ Participate in wellness program } & \multirow{3}{*}{3.90} & -0.20 & -0.23 & \multirow{3}{*}{0.11} & -2.42 & 0.018 \\
\hline \multicolumn{2}{|c|}{ Faculty member 6 to 10 years } & & 0.15 & 0.16 & & 1.47 & 0.145 \\
\hline Faculty $m$ & o 15 years & & 0.32 & 0.27 & & 2.58 & 0.012 \\
\hline \multicolumn{2}{|c|}{ Faculty member more than 15 years } & & 0.12 & 0.13 & & 1.19 & 0.237 \\
\hline Multiple $R$ & 0.337 & & & & & & \\
\hline Multiple $R^{2}$ & 0.117 & & & & & & \\
\hline$F$ Ratio & 3.027 & & & & & & \\
\hline$D F$ & 4.987 & & & & & & \\
\hline Sig & 0.021 & & & & & & \\
\hline
\end{tabular}


participation in the employer-sponsored wellness program and years of experience rejected.

SRQ 4. What statistically significant relationship, if any, is there between the employer-sponsored wellness program participation status, years of experience at the job, and job satisfaction (JS)?

$H 4_{0}$ : There is no relationship between the employer-sponsored wellness program participation status, age, and job satisfaction (JS).

$H 4_{\mathrm{a}}$ : There is a relationship between the employer-sponsored wellness program participation status, age, and job satisfaction (JS).

Multiple linear regression analysis used to determine if participation in an employer-sponsored wellness program and the age of the faculty member could be used to predict job satisfaction. As age was an ordinal variable, the four categories were dummy coded to allow their inclusion in the multiple linear regression analysis. Table 8 presents the results of this analysis.

Six percent of the variance in job satisfaction was accounted for by participation in employer-sponsored wellness programs and years of experience, although this result was not statistically significant, $F(5,97)=1.21, p=0.308$. One independent variable, participation in employer-sponsored wellness programs, was a statistically significant predictor of job satisfaction $(\beta=-0.22, t=-2.13, p$ $=0.036)$, indicating that faculty members who did not participate in the employer-sponsored wellness programs tended to have higher levels of job satisfaction. None of the age categories was statistically significant predictors of job satisfaction. Based on this finding, the null hypothesis that job satisfaction not related to participation in employer-sponsored wellness programs and the age of the faculty member retained. Based on this finding, the null hypothesis that job satisfaction not related to participation in employer-sponsored wellness programs and the age of the faculty member retained.

The finding from this study mostly aligns with the need-satisfaction model of job characteristics, needs, attitudes, and behaviors to explain the relationship

Table 8. Multiple linear regression analysis-job satisfaction, participation in employer-sponsored wellness programs, and years of experience.

\begin{tabular}{ccccccc}
\hline Predictor & Constant & $\boldsymbol{b}$-Weight & $\boldsymbol{\beta}$-Weight & $\boldsymbol{R}^{2}$ & $\boldsymbol{t}$ & Sig \\
\hline Participate in wellness program & & -0.19 & -0.22 & -2.13 & 0.036 \\
Age 21 to 29 years & & 0.06 & 0.03 & 0.31 & 0.761 \\
Age 30 to 39 years & 3.93 & 0.11 & 0.10 & 0.06 & 0.92 & 0.360 \\
Age 40 to 49 years & & 0.08 & 0.08 & 0.72 & 0.476 \\
Age 60 and over & & 0.10 & 0.10 & 0.85 & 0.398
\end{tabular}

$\begin{array}{cc}\text { Multiple } R & 0.247 \\ \text { Multiple } R^{2} & 0.067 \\ \text { F Ratio } & 1.217 \\ D F & 5.977 \\ \text { Sig } & 0.308\end{array}$


between job satisfaction and job motivation [18]. The findings remain consistent with job characteristics, needs, attitudes, and behavior. Within the review of literature, one key factor associated with the negative relationship between job satisfaction and participation in the employer-sponsored wellness program. Wellness programs offered by management often fail because they do not reflect the personal preferences of the employees [7]. An excellent way to overcome some of the factors is to involve the employees in designing the program [14]. The strategy encourage active participation in the program, and also offers the employees a sense of ownership, which is inherently empowering [7]. In the doctoral study, the results of the findings indicate that a negative relationship exists between job satisfaction and participation in the employer-sponsored wellness program.

\section{Application to Professional Practice}

This research is valuable to the federal government, state university systems, board of trustees, university administrations, and university faculty. The study results in present university decision-makers with information on the importance of university-sponsored wellness program. The results of this study may add to the body of knowledge concerning the relationship between employer-sponsored, wellness-program participation and job satisfaction for-profit college and university leaders.

University decision makers that create good wellness programs anticipate the results may correlate to job satisfaction and performance [3]. In comparing the performance of employees enrolled in wellness programs with the performance of those who are not, employees who participate in wellness programs are psychologically and physically more adept [3] [5] [6]. Employees who participate in wellness programs are more content with their jobs and are less likely to miss time at work. Field, \& Louw, 2012 and Sieberhagen et al. 2011 discovered a positive correlation between organization-sponsored wellness programs and worker satisfaction. Employee satisfaction associated with wellness programs is not necessarily a limit to for-profit businesses; the same result might exist in other organizational types [5].

Decision-makers of companies and organizations consider good employee health as an important goal. Good employee health increases job satisfaction, which in turn motivates employees to perform effetely and remain employed, accomplishing tasks enjoyable to them [7]. The state of mind encourages employees to give the company optimal performance and increases profit [4]. Employers' goals are to design a work strategy that cultivates a psychosocial climate in the organization characterized by the opportunity for career growth, advancement, and development [4]. Considering that employers adopt wellness programs with the intention to improve work relationships and to encourage employees, more research on the topic of employee wellness is necessary [5].

The results study showed that employees satisfied with their workplaces have 
an extensive social life because wellness programs sponsored by an organization at its worksite also help to create cohesiveness among employees as they interact on a personal level with their colleagues through participation in the programs. The result provided more opportunities for increased employee job satisfaction. The result of this study includes statistical data and numerous recommendations to university decision-makers on the positive relationship between employer-sponsored.

\section{Implications for Social Change}

The implications for positive social change include providing university decision-makers with information on the impact of organization-sponsored employee wellness programs on employee job satisfaction. University decision-makers can address issues for example absenteeism, productivity, and presentism, which affect an organization's revenue and profitability. More important, state-sponsored nonprofit higher education institutional management personnel can focus on spending their budgets, the funds for some of which provided by taxes, in ways that are accountable to the public. As an implication for social change, the results of the study could provide the organizational management from a non-profit higher education organization with information to support the inclusion of wellness programs into the culture, and consequently into the tax-dollar budgets of their institutions.

\section{RECOMMENDATIONS FOR FURTHER RESEARCH}

University management may use the data from this study as a tool whether or not organization-sponsored wellness programs are most appropriate for the development and well-being of their human asset. University management should pay close to the result of this study, as well as evaluate which type of wellness program is best for their organization. University leaders should work closely with employees in designing various wellness programs. Employee's involvement strategies encourage active participation in the program, and include a sense of ownership to their employees, which is inherently empowering.

The results of this study also prove beneficial to administrators, supervisors, executives, and human resource managers in small or large for-profit colleges and universities. Scholars and practitioners who study job satisfaction and employee wellness practices may find the results interesting.

\section{RECOMMENDATIONS FOR BUSINESS PROFESSIONALS}

The results of the study could expand the option for future scholars to examine the effects of employee wellness programs on employee productivity, and by extension, profitability. In addition, a future scholar may wish to use a qualitative model to code what type of incentives boost employee participation in wellness programs and promote adherence to certain behaviors. Organizational wellness programs are designed to promote workers' well-being and, hence, their satisfaction. The same result could realize in other organization types, for example, the higher education workplace; however, limited evidence to support the notion. The results of the research may address gaps in the knowledge base re- 
garding the effects of employee wellness programs on employee productivity and profitability.

Job satisfaction is becoming a fundamental concern for employees' working environment. Studies have shown that job satisfaction affects absenteeism and organizational productivity, and as a result, it exerts a great impact on an organization [5]. This conclusion demands an evaluation of the wellness initiative to ascertain its usefulness in ensuring the wellbeing of employees [5]. The connection between employees' satisfaction and wellness programs area phenomenon with limited and unreliable documented studies, thus presenting a general problem in the business setting that needs scholarly research attention.

The results of other literature show that employees who participate in wellness programs are psychologically and physically fit compared to their counterparts. In addition, employees taking part in wellness packages are more contented in their jobs and have decreased absenteeism rates as compared to their fellow employees. Previous studies have shown that a positive correlation between organizations' sponsored wellness programs and workers' satisfaction exists. Organizational decision-makers depend on wellness programs in organizational life. A gap exists in knowledge regarding participation in organization-sponsored wellness programs and their effect on job satisfaction in higher educational facilities. Consequently, more research is necessary to ascertain whether if there is a relationship between organizations' sponsored wellness programs and employee satisfaction within the work environment of colleges and universities.

\section{Study Limitations}

This study had four limitations: 1) The sampling process of the current study. 2) Some faculty members do not actively participate in worksite wellness activities. 3) No possibility exists for determining which faculty member is more appropriate than others to participate in worksite wellness activities. 4) Some faculty members who participate in worksite wellness activities could present the benefits of the program with less enthusiasm than the program deserves. Other faculty members might exaggerate the benefits. The results of the study would demonstrate the cause and effect relationships between variables.

\section{Conclusions}

The results of this correlational study did not predict job satisfaction among employees who participated in wellness programs. Faculty who were not participating in the wellness program tended to have higher levels of job satisfaction. The relationship between gender and job satisfaction was in a negative direction, indicating that females were more likely than males to have higher levels of job satisfaction. A positive relationship was found between being a faculty member for 11 to 15 years and job satisfaction, indicating that faculty who had been employed between 11 and 15 years were more likely to have higher levels of job satisfaction which was the purpose of this correlational study. University leaders 
should use the findings of the current study to further question the impact of organization-sponsored employee wellness programs on employee job satisfaction. Job satisfaction is becoming a fundamental concern for employees' working environment. An employee satisfied with his or her vocation is likely to motivate and dedicate to his or her work. However, dissatisfied employees will always seek ideas to stay away from work and to shirk their responsibilities [2].

Employees participating in wellness packages are more contented in their jobs with a decrease in the absenteeism rate compared to other employees. Previous studies have shown that a positive correlation between organizations' sponsored wellness programs and workers' satisfaction exists. Organizational decision-makers are depending on wellness programs into organizational life [10]. A gap exists in knowledge regarding participation in organization-sponsored wellness programs and their effect on job satisfaction in the workplace. Consequently, more research is necessary to ascertain whether a relationship exists between organizations' sponsored wellness programs and employee satisfaction within that work environment.

\section{Conflicts of Interest}

The authors declare no conflicts of interest regarding the publication of this paper.

\section{References}

[1] Connolly, K.M. and Myers, J.E. (2012) Wellness and Muttering: The Role of Holistic Factors in Job Satisfaction. Journal of Employment Counseling, 40, 152-160. https://doi.org/10.1002/j.2161-1920.2003.tb00866.x

[2] Akmal, F., Zainol, F.A., Mansor, M. and Ghazali, Z. (2012) Recreational Program and Its Association with Job Satisfaction. Asian Social Science, 8, 172. https://doi.org/10.5539/ass.v8n13p172

[3] Kalliath, T., Kalliath, P. and Kossek, E.E. (2012) Achieving Employee Wellbeing in a Changing Work Environment. International Journal of Manpower.

[4] DeJoy, D.M., Wilson, M.G., Vandenberg, R.J., McGrath-Higgins, A.L. and Griffin-Blake, C.S. (2010) Assessing the Impact of Healthy Work Organization Intervention. Journal of Occupational and Organizational Psychology, 83, 139-165. https://doi.org/10.1348/096317908X398773

[5] Field, C. and Louw, J. (2012) A Theory-Driven Evaluation of a Wellness Initiative. $S A$ Journal of Human Resource Management, 10, 1-8. https://doi.org/10.4102/sajhrm.v10i3.427

[6] Sieberhagen, C., Els, C. and Pienaar, J. (2011) Management of Employee Wellness in South Africa: Employer, Service Provider and Union Perspectives. SA Journal of Human Resource Management, 9, 1-14. https://doi.org/10.4102/sajhrm.v9i1.305

[7] Spreitzer, G. and Porath, C. (2012) Creating Sustainable Performance. Harvard Business Review, 90, 92-99. http://www.hbr.org

[8] Willis North America (2011) The Willis Health and Productivity Survey 2011. http://www.willis.com

[9] Avey, J.B., Luthans, F. and Jensen, S.M. (2009) Psychological Capital: A Positive Resource for Combating Employee Stress and Turnover. Human Resource Management, 48, 677-693. https://doi.org/10.1002/hrm.20294 
[10] Muya, M., Katsuyama, K., Ozaki, F. and Aoyama, H. (2014) Development of a Scale Measuring the Job Satisfaction of Japanese Hospital Nurses. Japan Journal of Nursing Science, 11, 160-170. https://doi.org/10.1111/jins.12017

[11] Maguad, B.A. (2006) The Modern Quality Movement: Origins, Development and Trends. Total Quality Management \& Business Excellence, 17, 179-203. https://doi.org/10.1080/14783360500450608

[12] Levitt, S.D. and List, J.A. (2011) Was There Really a Hawthorne Effect at the Hawthorne Plant? An Analysis of the Original Illumination Experiments. American Economic Journal: Applied Economics, 3, 224-238. https://doi.org/10.1257/app.3.1.224

[13] Howard, K.Z. (2012) Wellness Incentive Strategies that Work. Benefits Magazine, 49, 16-20.

[14] Benza, J. (2012) Optimizing Employee Engagement to Improve Health and Productivity-And Cut Costs. Employee Benefit Plan Review, 67, 13-14.

[15] Decker, S.L. (2012) In 2011 Nearly One-Third of Physicians Said They Would Not Accept New Medicaid Patients, But Rising Fees May Help. Health Affairs, 31, 1673-1679. https://doi.org/10.1377/hlthaff.2012.0294

[16] Jiang, K., Lepak, D.P., Hu, J. and Baer, J.C. (2012) How Does Human Resource Management Influence Organizational Outcomes? A Meta-Analytic Investigation of Mediating Mechanisms. Academy of Management Journal, 55, 1264-1294. https://doi.org/10.5465/amj.2011.0088

[17] Kortum, E., Leka, S. and Cox, T. (2011) Perceptions of Psychosocial Hazards, Work-Related Stress and Workplace Priority Risks in Developing Countries. Journal of Occupational Health, 53, 144-155. https://doi.org/10.1539/joh.O10016

[18] Salancik, G.R. and Pfeffer, J. (1977) An Examination of Need-Satisfaction Models of Job Attitudes. Administrative Science Quarterly, 22, 427-456. https://doi.org/10.2307/2392182

[19] Sadri, G. and Bowen, C.R. (2011) Meeting Employee Requirements: Maslow's Hierarchy of Needs Is Still a Reliable Guide to Motivating Staff. Industrial Engineer, 43, 44-49.

[20] Klassen, R.M. and Chiu, M.M. (2010) Effects on Teachers' Self-Efficacy and Job Satisfaction: Teacher's Gender, Years of Experience, and Job Stress. Journal of Educational Psychology, 102, 741-756. https://doi.org/10.1037/a0019237

[21] Bozeman, B. and Gaughan, M. (2011) Job Satisfaction among University Faculty: Individual, Work, and Institutional Determinants. The Journal of Higher Education, 82, 154-186. https://doi.org/10.1353/jhe.2011.0011

[22] Schultz, A.B., Chen, C.Y. and Edington, D.W. (2009) The Cost and Impact of Health Conditions on Presenteeism to Employers. Pharmacoeconomics, 27, 365-378. http://www.umich.edu/ hmrc/research/pdf/cost https://doi.org/10.2165/00019053-200927050-00002

[23] World Health Organization (1948) Definition of Health. Preamble to the Constitution of the World Health Organization as Adopted by the International Health Conference. Official Records of the World Health Organization, No. 2, 100. http://www.who.int/about/

[24] Kemp, E., Kopp, S.W. and Kemp, E.C. (2013) Take This Job and Shove It: Examining the Influence of Role Stressors and Emotional Exhaustion on Organizational Commitment and Identification in Professional Truck Drivers. Journal of Business Logistics, 34, 33-45. https://doi.org/10.1111/jbl.12008 
[25] Maslow, A.H. (1954) Motivation and Personality. Harper, New York.

[26] Crum, A. (2011) Evaluating a Mindset Training Program to Unleash the Enhancing Nature of Stress. In: Academy of Management Proceedings, Volume 2011, Academy of Management, Briarcliff Manor, New York, 1-6. https://doi.org/10.5465/ambpp.2011.65870502

[27] Lazarus, R.S. (1989) Psychological Stress in the Workplace. Journal of UOEH, 11, 528. https://www.ncbi.nlm.nih.gov/pubmed/2664957

[28] Van Ruysseveldt, J., Verboon, P. and Smulders, P. (2011) Job Resources and Emotional Exhaustion: The Mediating Role of Learning Opportunities. Work \& Stress, 25, 205-223. https://doi.org/10.1080/02678373.2011.613223

[29] Luthans, F., Avey, J.B., Avolio, B.J. and Peterson, S.J. (2010) The Development and Resulting Performance Impact of Positive Psychological Capital. Human Resource Development Quarterly, 21, 41-67. https://doi.org/10.1002/hrdq.20034

[30] Mahesh, V.S. (1993) Thresholds of Motivation: Nurturing Human Growth in the Organization. Tata McGraw-Hill Publishing Company, New York.

[31] Benson, S.G. and Dundis, S.P. (2012) Understanding and Motivating Health Care Employees: Integrating Maslow's Hierarchy of Needs, Training and Technology. Journal of Nursing Management, 11, 315-320. https://doi.org/10.1046/j.1365-2834.2003.00409.x

[32] Wolever, R.Q., Bobinet, K.J., McCabe, K., Mackenzie, E.R., Fekete, E., Kusnick, C.A. and Baime, M. (2012) Effective and Viable Mind-Body Stress Reduction in the Workplace: A Randomized Controlled Trial. Journal of Occupational Health Psychology, 17, 246-258. https://doi.org/10.1037/a0027278

[33] Spector, P.E. (1985) Measurement of Human Service Staff Satisfaction: Development of the Job Satisfaction Survey. American Journal of Community Psychology, 13, 693. https://doi.org/10.1007/BF00929796

[34] Adiele, E.E. and Abraham, N. (2013) Achievement of Abraham Maslow's Needs Hierarchy Theory among Teachers: Implications for Human Resource Management in the Secondary School System in Rivers State. Journal of Curriculum and Teaching, 2, 141-144. https://doi.org/10.5430/jct.v2n1p140

[35] Smith, P.C. (1969) The Measurement of Satisfaction in Work and Retirement: A Strategy for the Study of Attitudes. Rand McNally, Chicago, IL.

[36] McIntyre, S.E. and McIntyre, T.M. (2010) Measuring Job Satisfaction in Portuguese Health Professionals: Correlates and Validation of the Job Descriptive Index and the Job in General Scale. International Journal of Selection and Assessment, 18, 425-431. https://doi.org/10.1111/j.1468-2389.2010.00524.x

[37] Dhammika, K.A.S., Ahmad, F.B. and Sam, T.L. (2012) Job Satisfaction, Commitment and Performance: Testing the Goodness of Measures of Three Employee Outcomes. South Asian Journal of Management, 19, 7-22.

[38] Marshall, C. and Rossman, G.B. (2014) Designing Qualitative Research. Sage Publications, New York.

[39] Frels, R.K. and Onwuegbuzie, A.J. (2013) Administering Quantitative Instruments with Qualitative Interviews: A Mixed Research Approach. Journal of Counseling \& Development, 91, 184-194. https://doi.org/10.1002/j.1556-6676.2013.00085.x

[40] Szyjka, S. (2012) Understanding Research Paradigms: Trends in Science Education Research. Problems of Education in the 21 st Century, 43, 110-118.

http://www.pecob.eu 


\section{Appendix A: The Job Satisfaction Survey Instrument}

Opening Questions: Eligibility Criteria

Instructions: If you agree to participate in this research study, please answer the following eligibility criteria questions by clicking on the mark next to the response that best describes you, or is most applicable to your current employment.

1. Informed consent to participate: I have read and understood the informed consent document and hence agree to participate in this research study voluntarily.

- Yes

- No (If no, end of the survey.)

2. Are you 18 years of age or older?

- Yes

- No (If a person indicated no, end of the survey.)

3. Are you a faculty member at college or university in the United State?

- Yes

- No (If a person indicated no, end of the survey.)

4. Does your college or university have an organization-sponsored employee wellness program?

- Yes

- No (If no, end of the survey.)

Demographic Variables

Instructions: The collection of your demographic is necessary for testing the hypotheses of this research study. Please answer the following questions by clicking on the mark next to the response that best describes you or type your answer.

1. What is your gender?

_ Male

_ Female

\section{What is your age?}

Type in the answer

\section{How many years have you been a faculty member?}

Type in the answer 


\section{Do you participate in the university's wellness program?}

Type in the answer

5. How long have you been participating in the university's wellness program?

Duration

Not Applicable

Job Satisfaction Survey by Spector 1994

\begin{tabular}{|c|c|c|c|c|c|}
\hline 1 & 2 & 3 & 4 & 5 & 6 \\
\hline $\begin{array}{c}\text { Strongly } \\
\text { Disagree }\end{array}$ & $\begin{array}{c}\text { Moderately } \\
\text { Disagree }\end{array}$ & $\begin{array}{c}\text { Slightly } \\
\text { Disagree }\end{array}$ & $\begin{array}{c}\text { Slightly } \\
\text { Agree }\end{array}$ & $\begin{array}{c}\text { Moderately } \\
\text { Agree }\end{array}$ & $\begin{array}{c}\text { Strongly } \\
\text { Agree }\end{array}$ \\
\hline
\end{tabular}

\begin{tabular}{|c|c|c|c|c|c|c|}
\hline $\begin{array}{l}\text { Place a check mark in the column that matches the extent to which you } \\
\text { feel that you are at risk in each of the following situations: }\end{array}$ & 1 & 2 & 3 & 4 & 5 & 6 \\
\hline \multicolumn{7}{|l|}{ 1. I receive a fair wage. } \\
\hline \multicolumn{7}{|l|}{ 2. Too little chance for promotion on my job exists. } \\
\hline \multicolumn{7}{|l|}{ 3. My supervisor is quite competent in doing their job. } \\
\hline \multicolumn{7}{|l|}{ 4. I am not satisfied with the benefits I receive. } \\
\hline \multicolumn{7}{|l|}{ 5. When I do a good job, I receive the recognition I should receive. } \\
\hline \multicolumn{7}{|l|}{ 6. Many of our rules and procedures make doing a good job difficult. } \\
\hline \multicolumn{7}{|l|}{ 7. I like the people I work with. } \\
\hline \multicolumn{7}{|l|}{ 8. I sometimes feel my job is meaningless. } \\
\hline \multicolumn{7}{|l|}{ 9. Communication seems good within this organization. } \\
\hline \multicolumn{7}{|l|}{ 10. Raises are too rare. } \\
\hline \multicolumn{7}{|l|}{ 11. Those who do well on the job stand a fair chance of being promoted. } \\
\hline \multicolumn{7}{|l|}{ 12. My supervisor is unfair to me. } \\
\hline \multicolumn{7}{|l|}{ 13. The benefits we receive are as good as most other organizations offer. } \\
\hline \multicolumn{7}{|l|}{ 14. I do not feel the work I do receives appreciation. } \\
\hline \multicolumn{7}{|l|}{$\begin{array}{l}\text { 15. The incompetence of some people I work with seldom blocks my } \\
\text { effort to do a good job. }\end{array}$} \\
\hline \multicolumn{7}{|l|}{$\begin{array}{l}\text { 16. I find I have to work harder at my job because of the incompetence } \\
\text { of other employees. }\end{array}$} \\
\hline \multicolumn{7}{|l|}{ 17. I like doing the things I do at work. } \\
\hline \multicolumn{7}{|l|}{ 18. The goals of the organization are not clear to me. } \\
\hline \multicolumn{7}{|l|}{ 19. I receive a fair wage. } \\
\hline \multicolumn{7}{|l|}{ 20. Too little chance for promotion on my job exists. } \\
\hline 21. My supervisor is quite competent in doing their job. & & & & & & \\
\hline 22. I am not satisfied with the benefits I receive. & & & & & & \\
\hline
\end{tabular}




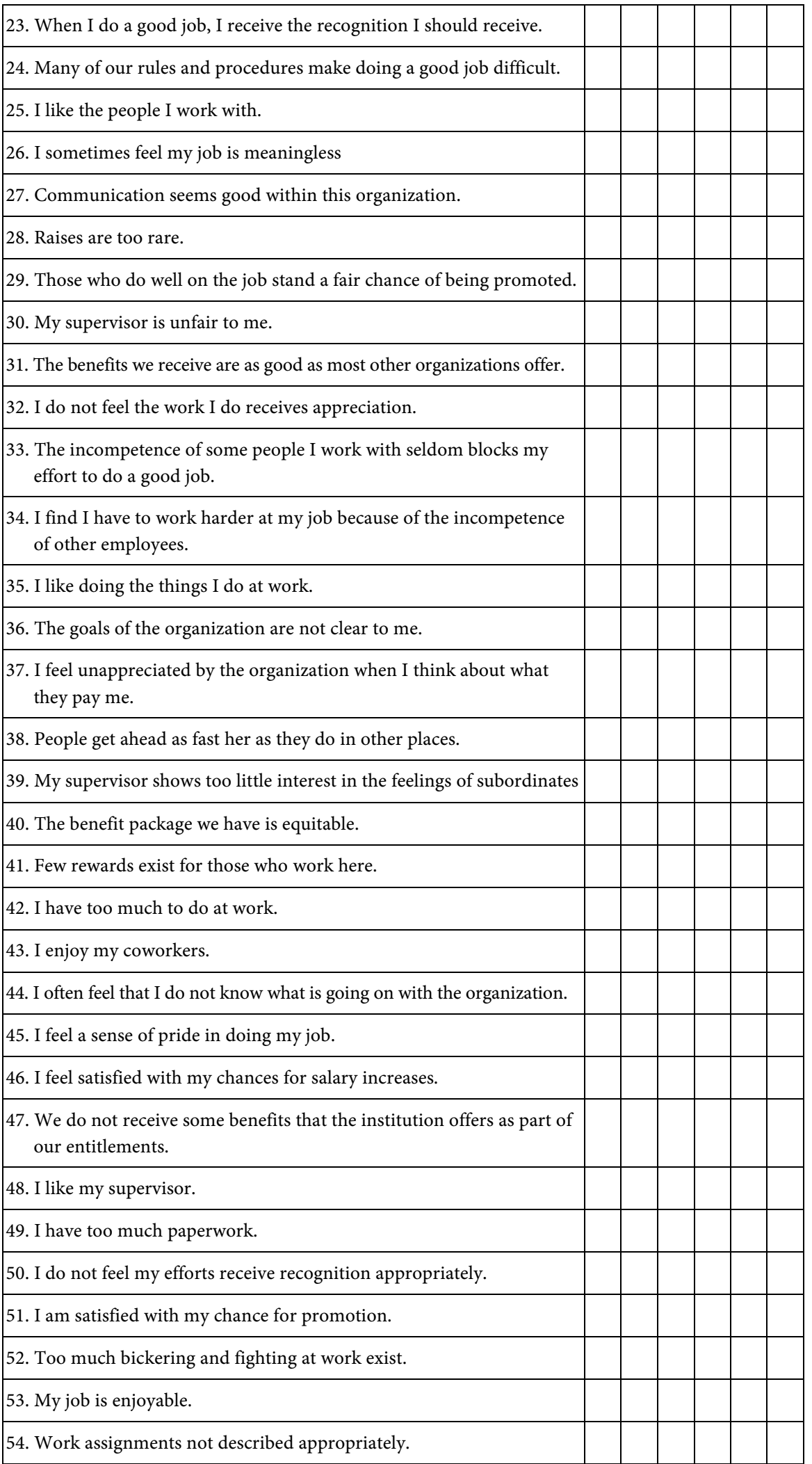




\section{Appendix B: Permission to Use the Survey}

You have my permission to use the JSS in your research. You can find copies of the scale in the original English and several other languages, as well as details about the scale's development and norms in the Scales section of my website http://shell.cas.usf.edu/ spector. I allow free use for noncommercial research and teaching purposes in return for sharing of results. This includes student theses and dissertations, as well as other student research projects. Copies of the scale can be reproduced in a thesis or dissertation as long as the copyright notice is included, "Copyright Paul E. Spector 1994, All rights reserved." Results can be shared by providing an e-copy of a published or unpublished research report (e.g., a dissertation). You also have permission to translate the JSS into another language under the same conditions in addition to sharing a copy of the translation with me. Be sure to include the copyright statement, as well as credit the person who did the translation with the year.

Thank you for your interest in the JSS, and good luck with your research.

Best,

Paul Spector, Distinguished Professor

Department of Psychology

PCD 4118

University of South Florida

Tampa, FL 33620

813-974-0357

pspector@usf.edu

$\underline{\text { http://shell.cas.usf.edu/ spector }}$ 